\title{
ECONOMIC PRICING OF COMPLEX PRODUCTS IN A COMPETITIVE CLOSED-LOOP SUPPLY CHAIN NETWORK UNDER UNCERTAINTY: A CASE STUDY OF COPS INDUSTRY
}

\author{
Omid Solgi $^{1, *}$, Alireza Taromi ${ }^{2}$, Jafar Gheidar-KhelJani $^{3}$ \\ AND EHSAN DEHGHANI ${ }^{1,4}$
}

\begin{abstract}
The development of technology, globalization of the economy and the unpredictable behavior of customers have eventuated in a dynamic and competitive environment in the complex product systems (CoPS) market. Besides, CoPS economic pricing is one of the key factors that dramatically reduces production costs and increases competitiveness. In this regard, this paper unveils a hybrid data envelopment analysis (DEA)-fuzzy mathematical model for economic pricing of CoPS in a competitive closed-loop supply chain network under uncertainty. In the first stage, different CoPS suppliers are evaluated exploiting a DEA model based on a set of economic, technical, and geographical criteria. The advantage of this evaluation is choosing appropriate suppliers, and reducing the complexity of the original model. Next, using a robust optimization model, the strategic and tactical decisions are simultaneously determined, providing a fully optimal solution to the model. In the concerned model, the costs and capacities of facilities are considered to be hemmed in by uncertainty. Eventually, to evaluate the proposed approach, a case study is conducted to derive the important managerial results. The numerical results corroborate that the presented robust model is capable of providing a stable structure under different realizations.
\end{abstract}

Received August 7, 2020. Accepted December 30, 2020.

\section{INTRODUCTION}

COPS mainly contributes to industrial development, economic growth, and national wealth generation in developed and developing countries. CoPS also demonstrates several specific features as a distinct category of industrial products compared to mass-produced consumer goods. These aspects have recently attracted much attention. In the reverse supply chain competition models, decisions in the reverse channel such as pricing (e.g., $[27,53,65,69])$ collection mode (e.g., $[16,69])$, collection rate, and reproduction method (e.g., [11,33]). It should

Keywords. Complex products and its subsystems, uncertainty, fuzzy robust optimization, pricing, data envelopment analysis, competitive closed-loop supply chain, simulation.

1 Department of Industrial Engineering, University of Science and Technology, Tehran, Iran.

2 Department of Industrial Engineering, University of Islamic Azad, Science and Research, Tehran, Iran.

3 Department of Industrial Engineering, University of Malek-e Ashtar University Technology, Tehran, Iran.

4 National Elites Foundation of Iran, Tehran, Iran.

* Corresponding author: omidsolg72@gmail.com 
be noted that, over the last 30 years, about $15 \%$ of world trade has been related to CoPS [31]. Moreover, among the various parts of CoPS, one of the requirements that can lead to the development of new technologies and cost savings is the economic pricing of CoPS, reducing costs and enhancing competitiveness [20]. It is worth noting that there are various definitions of CoPS that distinguish this domain from others. CoPS, for example, as the main complex consumer goods, plays a key role in the distribution of modern technology through the economy and facilitating financial, industrial, and technological processes in developed and developing countries [57]. There are also important strategic products in the CoPS area, which are essential for infrastructure, competition, technology, scientific advancement, new technologies, and value-added in any country. Examples of applications of complex products include the aerospace industry (e.g., $[2,14,15])$, the transportation (e.g., $[2,15,48])$, electronics industry (e.g., $[14,15,28,50])$, energy (e.g., $[14,15,32])$, sea drilling rigs, chemical plants, communications networks, racing cars, and smart buildings (e.g., $[2,15,28])$. Therefore, given the difference between this area and others, it is much more important to address this area. Also, according to the literature, most of the papers focusing on CoPS from 1995 to 2018 are based on qualitative methods and just a few studies have dealt with quantitative methods and mathematical modeling [57]. In this regard, Du and Guo [19] proposed the CoPS supplier selection life cycle to reduce purchase costs and operational risk. Liu et al. [43] presented a hierarchical model for optimal quality control strategies in the supply chain of supplier selection for CoPS production such as aircraft, warships, or satellites. Hongzhuan et al. [34] developed an optimal Nash costsharing model with the Stackelberg equilibrium for collaboration between the manufacturer and the supplier of CoPS equipment. Applied CoPS-related changes to copper production, Du and Guo [19] presented a multiobjective model to prevent and detect conflicts between CoPS products. Safdari Ranjbar et al. [57] discuss what has happened to CoPS in the past two decades, as well as the forward-looking developments that will occur in the future as governments enter. On top of that, Solgi et al. [59] considered a robust two-objective mathematical model for the resilience of supplier selection and order allocation of CoPS and its subsystems under uncertainty and risk disorder in their study. They also aimed to minimize the costs of supply chain selection in the first objective; and in the second objective, resilience strategies are considered for suppliers. Lastly, they conducted a case study on the supply of satellite components to evaluate the effectiveness and applicability of their model, by which important managerial results have derived. Moreover, it is worth noting that the development of technology, the globalization of the economy, and the unpredictable behavior of customers has led to a competitive and dynamic market environment [55,67]. These factors, with advanced infrastructure for e-commerce, change the form of competition in companies from individual competition to compete in the supply chain (e.g., $[3,8,55,67])$. For example, Microsoft (software supplier) and HTC (hardware supplier) are competing in a supply chain with other supply chains including Symbian (software provider) and Nokia (hardware supplier) [67]. In such cases, the following questions arise: Who will be the winner in this competition? What is the best network for the supply chain? How much does the winner get from the market? The motivation for this article is to find a way to address these questions. Besides, the closed-loop supply chain combines forward/reverse decisions, covering the entire life cycle. The supply chain also encompasses forward-looking logistics activities, ranging from raw materials to customers. The reverse supply chain also includes collection, reproduction, recycling and access activities [44,49,68]. Many manufacturers such as Xerox, Hewlett Packard, IBM, Ford, Caterpillar, and Timberland used reverse production and supply chain networks (e.g., [4,11,12,24, 36]). Ford saved $\$ 180000$ in costs by preventing cartridge disposal, in 1996 [65]. Also, Ford saved $\$ 1.2$ million in the period 1991-1997 by collecting and reproducing more than 332000 pounds of cartridges [65]. According to Gutowski et al. [26], the amount of recycling in the United States per year and each industry with 480000 direct employees is $\$ 50$ billion. Given the importance of reverse supply chain and economic attractions in this area, researchers have focused on designing a reverse supply chain network to maximize the value gained from integrating the forward/reverse supply chain [53]. On the other hand, competition as an important factor should be considered in designing the reverse supply chain network. Also, physical network design has a significant impact on overall supply chain performance. In addition, as a strategic decision, it has a limiting role in tactical and operational decisions. There is also a great deal of literature on the topic of closed-loop supply chains (e.g., $[9,46])$. It should be noted that despite the importance of competition in today's markets that force the supply 
chain to have a proper design, most studies in the literature do not consider competing factors in the network design phase. Rezapour and Farahani [55] and Farahani et al. [22] made a classification of models and solutions techniques based on the concept of competition in the supply chain design. Three types of competitions can be considered for reviewing the relevant literature [22,55]. (1) Static Competition: this type of competition involves mathematical model optimization in which new inputs make decisions about strategic factors such as facility's location (e.g., $[1,7,22,54-56])$. (2) Competition aggregated with a prediction: this type of competition is formulated with the Stackelberg game with a bi- or multilevel model. (3) Dynamic Competition: in this type of competition, existing competitiveness changes following the entry of new competitors. While supply chain strategy decisions (e.g., location or number of facilities) cannot be changed due to the high need for investment, competing for characteristics influence tactical level decisions such as price and service level. As can be seen, only a small proportion of the literature was devoted to competition between chains and most of the focuses were on competition between two components of a chain. Therefore, a method should be adopted to compete between chains McGuire and Staelin [45] were one of the first who focused on the competition between two chains. Wu and Chen [66] presented a model for competition between the two chains, considering inventory and return policies. Boyaci and Gallego [8] modeled the competition between two chains with a wholesaler and a retailer. They concluded that to maximize profits, both supply chain coordination require a strategy. Zhang [68] provided a general framework for the competitive supply chain; he also introduced an unsteady inequality model for the supply chain economic model, in which the supply chain was heterogeneous for different markets. Xiao and Yang [67] presented a game theory model of cost and service competition between two chains with demand uncertainty. Anderson and Bao [3] considered the price competition between two chains with linear demand function and distinct structure in integrated and decentralized vertical cases. They analyzed the effect of different price levels on market players' profits. It is worth noting that most competing models do not consider strategic decisions for rival chains and assume that the chain structure is fixed and predetermined. Most of the articles presented in the literature have focused on the forward chain under certain conditions, including return management in supply chain models that add further decision variables to the model. These variables are related to reverse flow, quantities of recycled materials, number of recycling centers, prices of recycled products, increasing the complexity of the model. On the other hand, integrating the forward and backward decisions avoids the suboptimal resulting from separate decision-making [42,64]. However, the dynamic nature and complexity of the supply chain imposes many uncertainties, thereby severely affecting the overall function of those supply chains [62]. Ho [30] divided the uncertainty affecting real phenomena into two groups: (1) environmental uncertainty and (2) systemic uncertainty. Environmental uncertainty in the supplychain concept relates to demand and supply uncertainties that depends on supplier performance and customer behavior. Though, system uncertainty is related to uncertainties in production, distribution, collection, and recycling which can be attributed to uncertainty in delivery time, production costs, and the actual capacity of different processes. Also, it is believed that the strategic horizon of supply chain network design dramatically increases the impact of uncertainties. Besides, Dekker et al. [18] argued that the issue of backward supply chain uncertainty is more important given the more difficult estimation and quality control of the quantity of returned products. Therefore, the importance of this kind of uncertainty has led researchers to consider this kind of uncertainty in the reverse supply chain [38]. The implication is that, according to Liu and Iwamura [40] , uncertainty can be found in both probability and possibility. For probability, the distribution function can be found through experiments and probabilistic planning approaches are used to deal with uncertaint. Possibility theory is used to evaluate mental analyses, where we are confronted with some unknown parameters. When the possibility of distribution is used, the model will have imprecise parameters. Liu and Lwamura [40] also asserts that, in these cases, possibility planning and fuzzy mathematical planning can be applied to optimize decisions as an efficient tool. However, there are two major problems with the probability approach. First, in many cases, there is insufficient data for historical parameters in the deterministic parameters. Therefore, we can rarely obtain a real and accurate distribution of certain parameters. Second, the use of probability planning dramatically increases the computational complexity of the problem. After all, to secure the optimal response against existing uncertainties and to establish a robust structure for the supply chain, it is incumbent upon to 
consider changes in parameters in the long-term horizon [41]. All of this leads to a robust solution that considers both the feasibility and optimality robustness simultaneously. The robust optimization approach provides a riskaverse and responsive approach that is not too sensitive to parameter changes. Lastly, since market demand for each chain is price dependent, the fuzzy theory is used to deal with uncertainty. Given the above-mentioned discussions, the motivation of this paper is to consider an economical pricing model for complex products and its subsystems in a competitive closed-loop supply chain network under uncertainty. Summary of innovations that distinguish this research from other studies and can enrich the literature in this field is as follows:

- Due to the DEA methods, the approach presented in this paper can increase the distinction and difference between CoPS decision options by applying efficient and inefficient frontier information. Using the applied DEA technique, CoPS suppliers are evaluated based on a set of economic, technical, and geographical criteria, which has two advantages. First, appropriate CoPS suppliers are selected; and second, by eliminating inappropriate suppliers, complexity, which is one of the fundamental problems of mathematical models, is reduced.

- A robust fuzzy model is applied to deal with the inherent uncertainty in the parameters.

- Unlike articles presented in the literature, this article uses a quantitative model to formualte the concerned problem.

- The concerned model is capable of taking into account the pricing decisions.

- The proposed model is one of the first papers in CoPS field, considering the competition in the supply chain network.

- The model is able to simultaneously take forward and reverse decisions in the CoPS supply chain network, providing a fully optimal solution to the model.

- Eventually, to evaluate the effectiveness and usefulness of the proposed method, a case study is conducted via which useful managerial results were obtained.

The structure of this study is as follows. The next section will discuss the methodology used in this paper. In Section 3, the DEA model is explained. In Section 4, the mathematical model is developed and the robust optimization approach is delineated in Section 5. Section 6 describes the used linearization method. In Section 7, a case study is conducted and finally, in Section 8, the conclusions and directions for future research are provided.

\section{Methodology}

As shown in Figure 1, the CoPS supply chain network design process is performed in two steps. In the first phase, the most suitable suppliers are identified and evaluated using a DEA model based on a set of technical, economic and geographical criteria (i.e., financial capability, network development capability, manpower capacity, delivery time and cost of delivery). Secondly, using a robust optimization model, the strategic and tactical decisions simultaneously are determined. The advantage of this step is the integrated decision-making process, providing a fully optimal solution to the model.

\section{Data envelopment AnAlysis method}

DEA can be used to evaluate efficiency levels within a group of organizations, where the performance of each unit is calculated against the number of units with the highest performance. This technique is based on a linear programming approach with the main purpose of comparing and evaluating the performance of some similar decision-making units (DMUs) with a different number of inputs and outputs. Farrell [23] began to measure the efficiency of a manufacturing unit by using a method such as measuring efficiency in engineering. What Farrell [23] used to measure efficiency was input and output. Farrell's study involved measuring technical efficiency, and an efficient production function's derivative. Later, Charnes et al. [10] developed Farrell's view and introduced a model called CCR. Next, Banker [5] considered a model with the variable return to scale that was called the BCC model. 


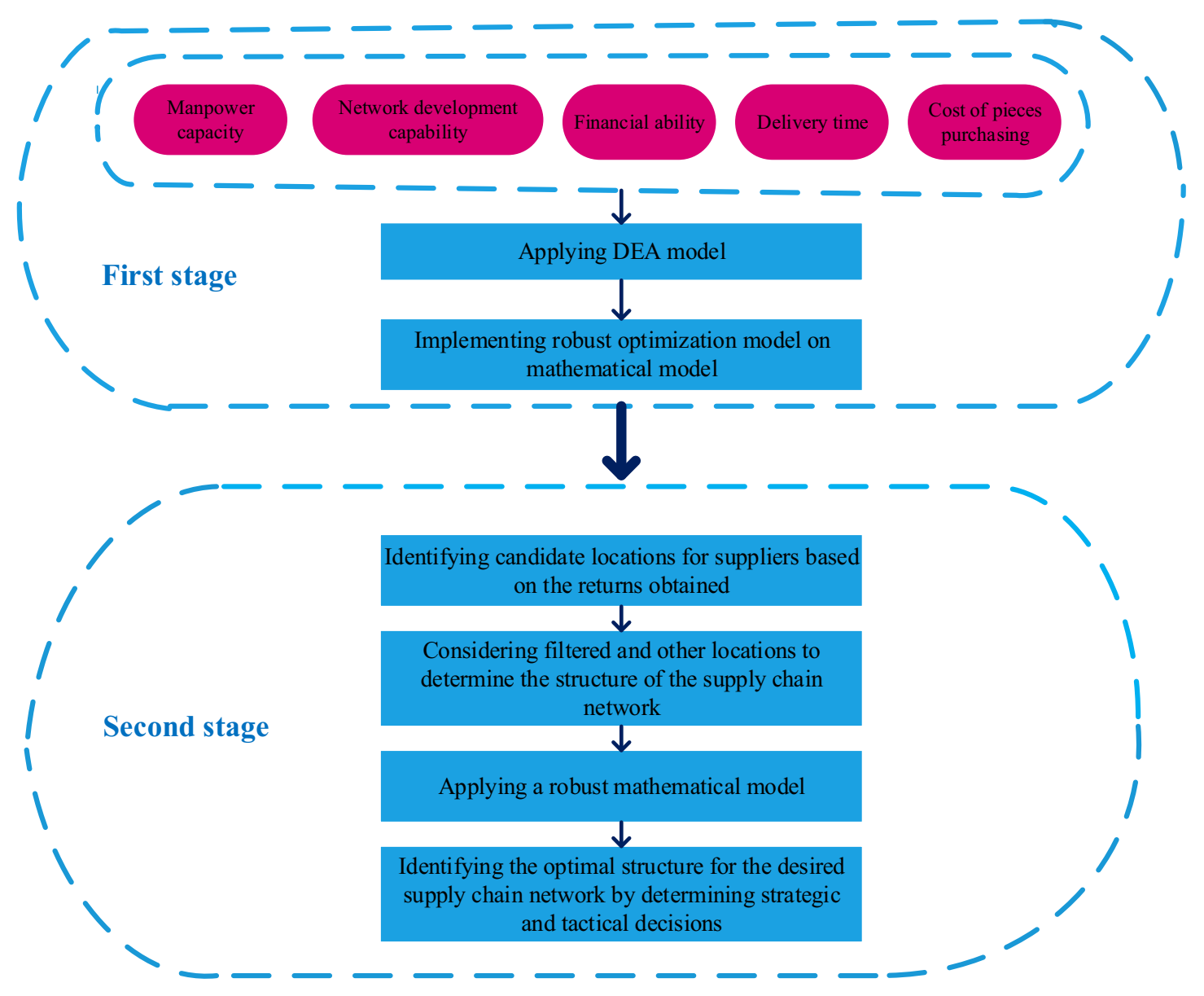

Figure 1. The general process of CoPS.

Reviewing several methods used in this field, the method of comparing good and bad DMUs simultaneously was chosen (e.g., $[58,61])$. In this study, the method presented by Shen et al. [58] is used to appraise different prices for COPS suppliers. Unlike other groups, the methods of this group are not restricted to a particular group and can be applied to different issues. Shen et al. [58] used an index that measures the distance between efficient and inefficient frontiers to enhance the power of DEA differentiation. In the proposed method, standard and reverse DEA are applied simultaneously to provide more information on frontiers. This enhances the strength of differentiation as well as leads to a better ranking. A description of employed approach is presented as follows:

Suppose there are $n$ DMUs so that their index is represented by $c(c=1, \ldots, n)$. Also, the inputs and outputs of the DEA model for the DMUs are respectively $x_{d c}(d=1, \ldots, g)$ and $y_{e c}(e=1, \ldots, q)$. The following model shows the standard DEA model:

$$
\begin{gathered}
\text { Min } h_{b l}^{*}=\theta_{l} \\
\qquad \sum_{c=1}^{n} x_{d c} \lambda_{c} \leq \theta_{l} x_{d l}, d=1, \ldots, g \\
\sum_{c=1}^{n} y_{e c} \lambda_{c} \geq y_{e l}, \quad e=1, \ldots, q
\end{gathered}
$$




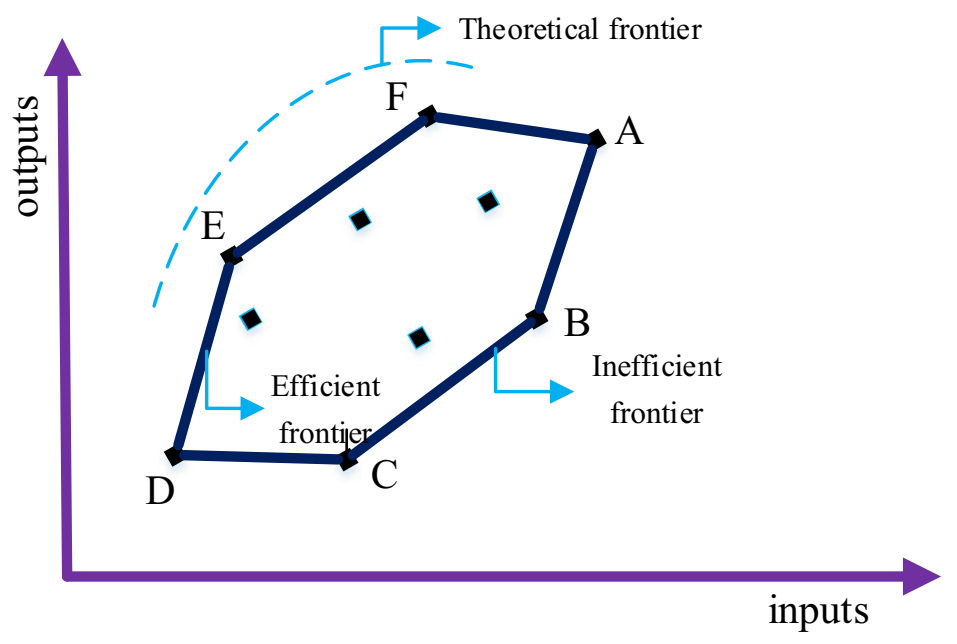

FiguRE 2. Graphical representation of efficient and inefficient frontiers.

$$
\begin{aligned}
& \lambda_{c} \geq 0, c=1, \ldots, n \\
& \theta_{l} \text { unconstrained. }
\end{aligned}
$$

Also the reverse DEA is as follows:

$$
\begin{aligned}
\operatorname{Max} & h_{w l}^{*}=\theta_{l} \\
& \sum_{c=1}^{n} x_{d c} \lambda_{c} \geq \theta_{l} x_{d l}, d=1, \ldots, g \\
& \sum_{c=1}^{n} y_{e c} \lambda_{c} \leq y_{e l}, e=1, \ldots, q \\
& \lambda_{c} \geq 0, c=1, \ldots, n \\
& \theta_{l} \text { unconstrained. }
\end{aligned}
$$

Thus, $\theta_{l}$ is the return value of the DMU $l ; x_{d l}$ and $y_{e l}$ are the inputs and outputs of the decision unit (the DMU $l$ ) and $\lambda_{c}$ is the weight of the dual attributed to all inputs and outputs of the DMU $c$.

Both the above-mentioned models are solved for the decision-making unit $l$ to obtain $h_{w l}^{*}$ and $h_{b l}^{*}$ efficiency scores. In other words, these two models are solved $n$ times to determine the frontiers. Specifically, the standard and reverse DEA models create efficient and inefficient frontiers, respectively. Figure 2 shows the efficient and inefficient frontiers geometrically.

As can be seen, the standard model of DEA employs the best decision-making unit of $D, E, F$, and $A$ to build an efficient frontier; and the inverse model of DEA uses the worst-case of DMUs $A, B, C$, and $D$ to form an inefficient frontier. The following index is calculated for each decision-making unit to use both frontier's information efficiently and aggregate the efficiency scores of the efficient and inefficient DEA models.

$$
h i_{l}^{*}=\frac{\left[h_{b l}^{*}+\left(1-\frac{1}{h_{w l}^{*}}\right)\right]}{2} .
$$

Note that if the decision-making unit $l$ is on the inefficient frontier (e.g., the DMUs $B$ and $C$ ), then $h_{w l}^{*}=1$ and $h i_{l}^{*}=\frac{h_{b l}^{*}}{2} \leq \frac{1}{2}$; and if it is on both frontiers (e.g., DMUs $A$ and $D$ ), then we will have, $h_{w l}^{*}=1$, and $h_{b l}^{*}=1$ then $h i_{l}^{*}=\frac{1}{2}$. By the way, if the decision-making unit is only on the efficient frontier (i.e., the decision unit 
$F$ and $E$ ), then $h i_{l}^{*}$ will be greater than 0.5 , making this decision unit more efficient than the other DMUs on both frontiers.

\subsection{Criteria used in data envelopment analysis}

Based on different expert opinion, a set of technical, geographical, and social criteria was used to evaluate suppliers. In this study, the criteria that were more desirable to rise were considered as output, and on the other hand, the criteria that are desirable to diminish are considered as input. Ultimately, the options that give higher scores are better rated and rank first. Considering a minimum threshold value, each option that has a higher value than threshold value will be selected.

\section{- Financial ability}

This criterion is important in this respect, the better the financial ability of the supplier, because it can provide better performance in financing for different uses, the better conditions it can provide. This parameter will be considered as an output parameter because it is more desirable to increase it.

\section{- Network development capability}

A supplier which has the power to develop new products and is capable of gaining more knowledge in this area can develop the network and lowering the costs. Therefore, since the rise in this criterion is appropriate, then this criterion is considered as the output.

\section{- Manpower capacity}

In this criterion, the expertise, skills, experience and level of literacy of the employees are considered. The greater the capacity of the manpower, the better the supplier will be able to supply in various fields. Higher values of this criterion are more desirable. Hence, this criterion is an output criterion.

\section{- Delivery time}

This criterion is important in terms of planning. With more precise planning, we will have less delivery time that means a reduction in the supply chain deficiencies and a higher flow rate in the network. Smaller values of this criterion are more desirable, therefore, this criterion is considered as an input.

\section{- Cost of supplying the pieces}

Any supplier who can provide the parts at a lower cost will have greater utility. Therefore, this criterion can also be considered as an input.

\section{Problem statement}

In this paper, competition between two closed-loop supply chains is investigated under uncertainty. There are several manufacturers, retailers, and recyclers in the supply chain, where retailers buy products from customers and transfer them to recyclers. Demands and returns in the supply chain, are price dependent and behave according to the Stackelberg game in a competitive environment. Price values are also determined by the use of Nash equations. For further explanation of the problem, consider two closed-loop supply chain networks with similar and highly stable products. Each supply chain is made up of manufacturers who sell the product at wholesale prices and retailers that sell the product to customers. In the backward supply chain, retailers buy used goods from customers and send them to recycling centers. After the products are separated at the recycling center, the recyclables are returned to the manufacturers. This supply chain system is a closed-loop the economic and environmental aspects, where the producer has two ways to meet the demand: first, production of new products and second the production of return products. Reproduced products are not very different from new products and can be sold in a single market at a shared price. That is, in addition to the forward 
supply chain, the reverse supply chain is also considered, which makes decisions more optimal. In other words, given the backward supply chain, the economic and environmental aspects are improved. Some supply chain models do not include pricing in the model, where the price is specified in the model and depends on two parameters of demand and profit. Furthermore, factors influencing pricing and pricing strategies as the model's constraints can be considered. In this study, price is a decision variable that will be determined by the model. In a competitive market, each agent's demand depends on his/her price and the competitor's price. Hence, a linear demand function will be used because of the following reasons: (1) a linear function is tractable; (2) a linear function is usually appropriate for a data set as proposed by Green [25] and Kurata et al. [39]; and (3) in the economics and marketing literature, the commonplace use of a linear form of demand that have an ascending function of the firm's given price and a descending function of competing prices (e.g., $[16,63,65,69])$. The used linear function is as follows:

$$
D_{i}\left(p_{i}, p_{t}\right)=\tilde{d}_{i}-\tilde{\beta}_{1 i} p_{i}+\tilde{\beta}_{2 i} p_{t} ; \quad i=1,2 ; t=3-i .
$$

The above relation $p_{i}$ is the retail unit price in the supply chain $i$ and $\tilde{d}_{i}$ is the potential product demand in supply chain $i$ (mathematically: the supply chain demand when both chains offer zero price). The relative value of $\tilde{d}_{i}$ describes comparative superiority in terms of customer access, price control, and service effectiveness. $\tilde{\beta}_{1 i}$ and $\tilde{\beta}_{2 i}$ are the elastic coefficients of the firm's price and the competitor's price, respectively.

$\tilde{\beta}_{1 i}$ shows the impact of supply chain prices on customer purchasing and demand; $\tilde{\beta}_{2 i}$ shows the impact of competing for supply chain goods on supply chain demand. Missing information and lack of sufficient knowledge make us use the stochastic distribution function to generate uncertain parameter values. Demand for each chain is more sensitive to the price of the chain itself than to competitors. The volume of second-hand goods collected depends on the number of retail sales paid to the customer over second-hand goods. The following linear function indicates that the number of retail transactions that give more money to second-hand goods will be greater.

$$
R_{i}\left(r p_{i}, r p_{t}\right)=\tilde{r}_{i}+\tilde{\beta}_{1 i}^{\prime} r p_{i}-\tilde{\beta}_{2 i}^{\prime} r p_{t} ; \quad i=1,2 ; t=3-i .
$$

Therefore, the issue of closed-loop supply chain design is a competition in which the volume of demand and the return on goods depend on competitive factors such as retail prices and prices of second-hand goods. Also, the assumptions of the problem are as follows:

- The cost of production in both chains is equal.

- Recycling centers buy second-hand goods from retailers at the same price.

- All customer's demands must be met and all second-hand goods must be recycled.

- The problem is modeled for a single-product period.

Before presenting the optimization model, the conceptual mathematical model is as follows:

\section{Maximizing Profit}

Production centers revenue + Retailer income - Fixed cost of construction

- Variable cost of transportation - Recycling costs

\section{Constraints}

- Meeting the demands.

- Determining the forward flow in the supply chain.

- Determining the backward flow in the supply chain.

- Meeting capacity constraints.

- Fulfilling nonnegative and correct variables constraints. 


\subsection{Formulation}

In this sub-section, the optimization model of the concerned problem is given. In doing so, the indices, parameters and decision variables used in the proposed model are first defined.

\section{Indices}

$i \quad$ Index of supply chain index.

$n \quad$ Index of potential locations of production centers.

$j$ Index of suitable centers for retailers.

$k$ Index of potential places for recycling centers.

\section{Parameters}

$V V_{n j} \quad$ Product sales revenue from production center $n$ to retailer center $j$.

$w w_{j k} \quad$ Sale revenue of recycled products from retailer center $j$ to the recycling center $k$.

$\tilde{f}_{n} \quad$ Fixed cost of building production center $n$.

$\tilde{c}_{k} \quad$ Fixed cost of recycling center $k$.

$\tilde{b}_{j} \quad$ Fixed cost of retail construction $j$.

$t \tilde{p}_{n j} \quad$ Shipping cost per unit from manufacturing center $n$ to retailer center $j$.

$t \tilde{r}_{j k} \quad$ Shipping cost per unit from retailer center $j$ to recycling center $k$.

$t \tilde{m}_{j k} \quad$ Shipping cost per unit of recycled goods from retailer center $j$ to recycling center $k$.

$\tilde{\varphi}_{k} \quad$ The cost of recycling per unit of product at the recycling center $k$.

$c \tilde{p}_{n} \quad$ The cost of recycling per unit of product at production center $n$.

$\tilde{c} r_{j} \quad$ Capacity of retailer center $j$.

$\tilde{c} m_{k} \quad$ The capacity of the recycling center $k$.

\section{Decision variables}

$x_{n j} \quad$ The volume of goods flow between production center $n$ and retailer center $j$.

$u_{j k} \quad$ The volume of second-hand goods flows between retailer center $j$ and recycling center $k$.

$m_{k n} \quad$ The volume of recycled goods from recycling center $k$ and production center $n$.

$p_{i} \quad$ Retail price in supply chain $i$.

$r p_{i} \quad$ The unit price of supply chain $i$.

$z_{n}= \begin{cases}1 & \text { if production center } n \text { is built } \\ 0 & \text { otherwise. }\end{cases}$

$y_{k}= \begin{cases}1 & \text { if recycling center } k \text { is built } \\ 0 & \text { otherwise. }\end{cases}$

$w_{j}= \begin{cases}1 & \text { if the retail center } j \text { is built } \\ 0 & \text { otherwise. }\end{cases}$

Now, the proposed optimization model is presented as follows:

$$
\begin{aligned}
\operatorname{Max} & Z_{2}=\sum_{n} \sum_{j} V V_{n j} x_{n j}+\sum_{j} \sum_{k} w w_{j k} u_{j k} \\
& -\sum_{n} \tilde{f}_{n} z_{n}-\sum_{k} \tilde{c}_{k} y_{k}-\sum_{j} \tilde{b}_{j} w_{j}-\sum_{n} \sum_{j} t \tilde{p}_{n j} x_{n j} \\
& -\sum_{j} \sum_{k} t \tilde{r}_{j k} u_{j k}-\sum_{k} \sum_{n} t \tilde{m}_{j k} m_{k n}-\sum_{k} \sum_{j} \tilde{\varphi}_{j k} u_{j k}
\end{aligned}
$$

s.t.

$$
\begin{aligned}
& \sum_{n} \sum_{j} x_{n j}=d_{2}-\beta_{12} P_{2}+\beta_{22} P_{1} \\
& \sum_{j} \sum_{k} u_{j k}=r_{2}+\beta_{12} r p_{2}-\beta_{22} r p_{1}
\end{aligned}
$$




$$
\begin{array}{ll}
\sum_{k} u_{j k} \leq \sum_{n} x_{n j} & \forall j \\
\sum_{j} u_{j k}=\sum_{n} m_{k n} & \forall k \\
\sum_{k} m_{k n} \leq \sum_{j} x_{n j} & \forall n \\
\sum_{k} m_{k n} \leq c \tilde{p}_{n} z_{n} & \forall n \\
\sum_{j} u_{j k} \leq \tilde{c} m_{k} y_{k} & \forall k \\
\sum_{n} x_{n j} \leq \tilde{c} r_{j} w_{j} & \forall j \\
x_{n j}, u_{n j}, m_{n j} \geq 0 & \forall n, j, k \\
z_{n}, y_{k}, w_{j} \in\{0,1\} & \forall n, k, j .
\end{array}
$$

Constraints (4.3)-(4.5) maximize the objective function of the supply chain profit. The first and second parts of the objective function represent the revenue of the production centers and the retailer revenue, respectively. Product centers sell products at retail prices and other parts of the objective function have fixed costs for construction, variable transportation, and recycling. Constraint (4.6) ensures that customer demand is met. Constraint (4.7) indicates the need to transfer recycled products from retailers to recycling centers. Constraint (4.8) refers to the limit on the maximum amount of the products shipped back to retailers, and the necessity to lower the amount of shipped back products than the production. Constraint (4.9) guarantees the equilibrium current flow for returned and recycled products. The maximum allowable amount of recycled products is shown by constraint (4.10). It should be noted that the products recycled from recycling centers must be at least equal to the quantities produced. Constraints (4.11)-(4.13) indicate capacity constraints in manufacturing centers, recycling centers and retailers and constraints (4.14) and (4.15) relate to the type of variables.

\section{RoBust-FUZZY OptimizATION}

In some real situations, especially for strategic decisions, there is not enough historical data or it is difficult to obtain the distribution of the parameters. In these situations, the parameters will face some kind of uncertainty called epistemic uncertainty, where fuzzy mathematical programming can be used to deal with such uncertainties.

Generally, fuzzy programming methods are divided into two classes, including flexible programming and possibilistic programming. In the flexible programming the flexibility in the target values of the objective function and the constraints will be controlled. On the other hand, in possibilistic programming imprecision in the parameters of the objective and constraint function are considered, being usually modeled based on decisionmaking subjective data with possibilistic distributions. Since our model only contains imprecise parameters, possibilistic programming can be used here.

In order to provide a stable structure for the supply chain and to make decisions that are less sensitive to changes, it seems necessary to consider changes in parameters over a long period $[6,41,47]$. This leads us to look for a robust answer that is feasible under various conditions (i.e., feasible robustness) and also makes the objective function close to the optimal answer (i.e., optimality robustness).

To achieve the benefits of both fuzzy and robust programming, Pishvaei et al. [51] proposed robust possibilistic planning. This method is based on the robust possibilistic chance-constrained programming and the trapezoidal possibility distribution, which is a more general form of the triangular form [13,37,51], is considered for the indeterministic parameters. Figure 3 shows this distribution.

It should be noted that in the proposed method, the feasibility and optimality robustness are optimized in addition to the average value of the possibility objective function. 


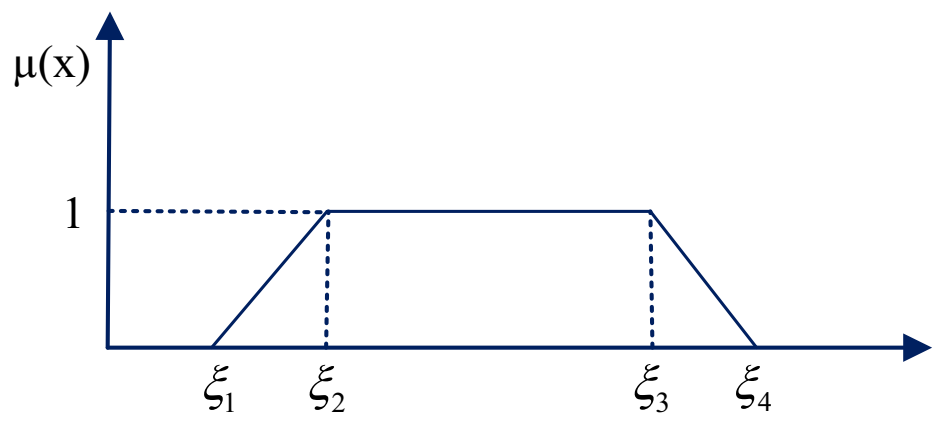

FIgURE 3. Trapezoidal possiblistic distribution for fuzzy parameter of $\xi$.

In the following, this robust optimization method will be explained. To make it easier to work, consider the following compact model:

$$
\begin{aligned}
\text { Min } & w=\tilde{f} z+\tilde{c} x \\
& A x \leq \tilde{U} z \\
B x & \leq 0 \\
N z & =1 \\
z & \in\{0,1\}, x \geq 0 \& \text { Integer. }
\end{aligned}
$$

In the above model, $\tilde{f}$ is the objective function coefficient and corresponds to the binary variable. $\tilde{c}$ is related to continuous variables and $\tilde{U}$ corresponds to the right coefficients in an uncertain constraint. By the way, matrices $A, B$, and $N$ are matrix coefficients. The $z$ and $x$ vectors are binary and continuous variables, respectively. The above-mentioned model assumes that the vectors $\tilde{f}, \tilde{c}$, and $\tilde{U}$ have epistemic uncertainty. Note that the measure of necessity, as a conservative fuzzy measure that is very close to certain conditions [51], is used to formulate the chance constraints of the imprecise parameters. The fuzzy mean value operator (i.e., $E[\cdot])$ is exploited to write the possibilistic function's co-objective. Given the description provided, the Possibilistic chance-constrained programming $(\mathrm{PCCP})$ is formulated as follows:

$$
\begin{aligned}
\text { Min } & E[w]=E[\tilde{f}] z+E[\tilde{c}] x \\
& B x \leq 0 \\
& N e c\{A x \leq \tilde{U} z\} \geq \alpha \\
& N z=1 \\
& z \in\{0,1\}, \quad x \geq 0 \& \text { Integer. }
\end{aligned}
$$

Thus, $\alpha$ is the least confidence level of chance constraint. The robust companion of the model is as follows $[21,29,35]$ :

$$
\begin{aligned}
\operatorname{Min} & E[w]=\frac{f_{1}+f_{2}+f_{3}+f_{4}}{4} z+\frac{c_{1}+c_{2}+c_{3}+c_{4}}{4} x \\
& B x \leq 0 \\
& A x \leq\left[\alpha U_{1}+(1-\alpha) U_{2}\right] z \\
& N z=1 \\
& z \in\{0,1\}, \quad x \geq 0 \& \text { Integer. }
\end{aligned}
$$


Based on the above model, the robust possibilistic chance-constrained programming can be formulated as follows:

$$
\begin{aligned}
\text { Min } o b j & =E[w]+\gamma\left(w_{\max }-w_{\min }\right)+\delta\left[\alpha U_{1}+(1-\alpha) U_{2}-U_{1}\right] z \\
B x & \leq 0 \\
A x & \leq\left[\alpha U_{1}+(1-\alpha) U_{2}\right] z \\
N z & =1 \\
z & \in\{0,1\}, \quad x \geq 0 \& \text { Integer } \quad 0.5<\alpha \leq 1 .
\end{aligned}
$$

Similar to the robust possibilistic chance-constrained programming model, the first part of the mean objective function shows $w$, which measures the average value of the overall system performance. The second part of the objective function, i.e., is $\gamma\left(w_{\max }-w_{\min }\right)$, shows the difference between two limit values of $w$. In other words, $w_{\max }$ and $w_{\min }$ are obtained as follows:

$$
\begin{aligned}
& w_{\max }=f_{4} z+c_{4} x \\
& w_{\text {min }}=f_{1} z+c_{1} x .
\end{aligned}
$$

Furthermore, $\gamma$ denotes the importance of this term compared to other terms of the objective function. In fact, it is intended to measure the optimality of the answer. The third term of the objective function, i.e., $\delta\left[\alpha U_{1}+(1-\alpha) U_{2}-U_{1}\right]$, denotes the feasible penalty function that is used to penalize a violation in constraints. In other words, $\left[\alpha U_{1}+(1-\alpha) U_{2}-U_{1}\right]$ represents the difference between the value used in the chance-constrained and the worst value of the parameter, where $\delta$ is the weight of the term in the objective function. Unlike the possibilistic chance constrained programming model, the confidence interval of chance constraint (i.e., $\alpha$ ) is a decision variable, whose value must be determined by the optimization model. Therefore, this new model avoids subjective judgment about the value of $\alpha$ and determines its overall optimal value. According to the given explanation, the objective function of the robust model considers three parts: (1) average performance, (2) optimality robustness, and (3) feasible consistency. Given the description, the proposed robust model is as follows:

$$
\begin{aligned}
\operatorname{Max} & Z_{2}=\sum_{n} \sum_{j} V V_{n j} x_{n j}+\sum_{j} \sum_{k} w w_{j k} u_{j k} \\
& -\sum_{n}\left(\frac{f_{n 1}+f_{n 2}+f_{n 3}+f_{n 4}}{4}\right) z_{n}-\sum_{n}\left(f_{n 4}-f_{n 1}\right) z_{n} \\
& -\sum_{k}\left(\frac{c_{k 1}+c_{k 2}+c_{k 3}+c_{k 4}}{4}\right) y_{k}-\sum_{k}\left(c_{k 4}-c_{k 1}\right) y_{k} \\
& -\sum_{j}\left(\frac{b_{j 1}+b_{j 2}+b_{j 3}+b_{j 4}}{4}\right) w_{j}-\sum_{j}\left(b_{j 4}-b_{j 1}\right) w_{j} \\
& -\sum_{n} \sum_{j}\left(\frac{t p_{n j 1}+t p_{n j 2}+t p_{n j 3}+t p_{n j 4}}{4}\right) x_{n j}-\sum_{j} \sum_{k}\left(t p_{n j 4}-t p_{n j 1}\right) x_{n j} \\
& -\sum_{j} \sum_{k}\left(\frac{t r_{j k 1}+t r_{j k 2}+t r_{j k 3}+t r_{j k 4}}{4}\right) u_{j k}-\sum_{j} \sum_{k}\left(t r_{j k 4}-t r_{j k 1}\right) u_{j k} \\
& -\sum_{k} \sum_{n}\left(\frac{t m_{j k 1}+t m_{j k 2}+t m_{j k 3}+t m_{j k 4}}{4}\right) m_{k n}-\sum_{k} \sum_{n}\left(t m_{j k 4}-t m_{j k 1}\right) m_{k n} \\
& -\sum_{k} \sum_{j}\left(\frac{\varphi_{j k 1}+\varphi_{j k 2}+\varphi_{j k 3}+\varphi_{j k 4}}{4}\right) u_{j k}-\sum_{k} \sum_{j}\left(\varphi_{j k 4}-\varphi_{j k 1}\right) u_{j k} \\
& -\left[\left(\alpha \alpha_{k}\right) c m_{1 k}+\left(1-\alpha \alpha_{k}\right) c m_{2 k}-c m_{1 k}\right] y_{k}-\left[\left(\varphi \phi_{j}\right) c r_{1 j}+\left(1-\varphi \varphi_{j}\right) c r_{2 j}-c r_{1 j}\right] w_{j}
\end{aligned}
$$




$$
-\left[\left(\beta \beta_{n}\right) c p_{1 n}+\left(1-\beta \beta_{n}\right) c p_{2 n}-c p_{1 n}\right] z_{n}
$$

s.t.

$$
\begin{aligned}
& \sum_{n} \sum_{j} x_{n j}=d_{2}-\beta_{12} P_{2}+\beta_{22} P_{1} \\
& \sum_{j} \sum_{k} u_{j k}=r_{2}+\beta_{12} r p_{2}-\beta_{22} r p_{1} \\
& \sum_{k} u_{j k} \leq \sum_{n} x_{n j} \\
& \sum_{j} u_{j k}=\sum_{n} m_{k n} \\
& \sum_{k} m_{k n} \leq \sum_{j} x_{n j} \\
& \sum_{k} m_{k n} \leq\left[\left(\beta \beta_{n}\right) c p_{1 n}+\left(1-\beta \beta_{n}\right) c p_{2 n}\right] z_{n} \\
& \sum_{j} u_{j k} \leq\left[\left(\alpha \alpha_{k}\right) c m_{1 k}+\left(1-\alpha \alpha_{k}\right) c m_{2 k}\right] y_{k} \\
& \sum_{n} x_{n j} \leq\left[\left(\varphi \phi_{j}\right) c r_{1 j}+\left(1-\varphi \varphi_{j}\right) c r_{2 j}\right] w_{j} \\
& x_{n j}, u_{n j}, m_{n j} \geq 0 \\
& z_{n}, y_{k}, w_{j} \in\{0,1\}
\end{aligned}
$$

$\forall n, j, k$

$\forall n, k, j$.

\section{LINEARIZATION}

The model (5.23)-(5.42) is in a nonlinear form. To avoid the computational complexity of the resulting model, nonlinear expressions are converted to linear form. Any nonlinear expression can be converted to a linear form by introducing a new variable and adding some constraints. For example, the non-linear expression $\alpha \alpha_{k} \times y_{k}$ is replaced by the new variable $\alpha y_{k}$, and the following constraints are added to limit its value:

$$
\begin{aligned}
0 & \leq \alpha y_{k} \leq \alpha \alpha_{k} \\
\alpha \alpha_{k}-M M_{k}\left(1-y_{k}\right) & \leq \alpha y_{k} \leq M M_{k} y_{k}
\end{aligned}
$$

where, $M M_{k}$ is a predetermined large number. If $y_{k}=1$, the value on the left of equation (6.1) is $\alpha \alpha_{k}$ and the value on the right will be a large positive number. Now given the upper limit value of the variable $\alpha y_{k}$ in equation (6.1), it is obvious that we will have $\alpha y_{k}=\alpha \alpha_{k}$. On the other hand, if $y_{k}=0$, the value on the left of the constraint (6.2) will be equal to a large negative number and the value of the right becomes zero. Hence, considering the lower limit value of equation (5.34), the value of $\alpha y_{k}$ is zero. Similarly, other nonlinear components are converted to their linear form as follows:

$$
\begin{aligned}
\varphi \phi_{j} w_{j} & =\varphi w_{j} \\
0 \leq \varphi w_{j} & \leq \varphi \phi_{j} \\
\varphi \phi_{j}-M M_{j}\left(1-w_{j}\right) & \leq \varphi w_{j} \leq M M_{j} w_{j} \\
\beta \beta_{n} z_{n} & =\beta z_{n} \\
0 \leq \beta z_{n} & \leq \beta \beta_{n} \\
\beta \beta_{n}-M M_{n}\left(1-z_{n}\right) & \leq \beta z_{n} \leq M M_{n} z_{n} .
\end{aligned}
$$


It should be noted that choosing a very large value for $M M$ increases the computational complexity. The appropriate value for this parameter goes back to the sample studied and the properties of the problem. In our case, as the capacities are set between two predefined values, this upper limit is considered as the value of $M M$.

According to the description given, the linear form of model (5.23)-(5.42) will be as follows:

$$
\begin{aligned}
\operatorname{Max} & Z_{2}=\sum_{n} \sum_{j} V V_{n j} x_{n j}+\sum_{j} \sum_{k} w w_{j k} u_{j k} \\
& -\sum_{n}\left(\frac{f_{n 1}+f_{n 2}+f_{n 3}+f_{n 4}}{4}\right) z_{n}-\sum_{n}\left(f_{n 4}-f_{n 1}\right) z_{n} \\
& -\sum_{k}\left(\frac{c_{k 1}+c_{k 2}+c_{k 3}+c_{k 4}}{4}\right) y_{k}-\sum_{k}\left(c_{k 4}-c_{k 1}\right) y_{k} \\
& -\sum_{j}\left(\frac{b_{j 1}+b_{j 2}+b_{j 3}+b_{j 4}}{4}\right) w_{j}-\sum_{j}\left(b_{j 4}-b_{j 1}\right) w_{j} \\
& -\sum_{n} \sum_{j}\left(\frac{t p_{n j 1}+t p_{n j 2}+t p_{n j 3}+t p_{n j 4}}{4}\right) x_{n j}-\sum_{j} \sum_{k}\left(t p_{n j 4}-t p_{n j 1}\right) x_{n j} \\
& -\sum_{j} \sum_{k}\left(\frac{t r_{j k 1}+t r_{j k 2}+t r_{j k 3}+t r_{j k 4}}{4}\right) u_{j k}-\sum_{j} \sum_{k}\left(t r_{j k 4}-t r_{j k 1}\right) u_{j k} \\
& -\sum_{k} \sum_{n}\left(\frac{t m_{j k 1}+t m_{j k 2}+t m_{j k 3}+t m_{j k 4}}{4}\right) m_{k n}-\sum_{k} \sum_{n}\left(t m_{j k 4}-t m_{j k 1}\right) m_{k n} \\
& -\sum_{k} \sum_{j}\left(\frac{\varphi_{j k 1}+\varphi_{j k 2}+\varphi_{j k 3}+\varphi_{j k 4}}{4}\right) u_{j k}-\sum_{k} \sum_{j}\left(\varphi_{j k 4}-\varphi_{j k 1}\right) u_{j k} \\
& -\left[\alpha y_{k} c m_{1 k}+c m_{2 k} y_{k}-\alpha y_{k} c m_{2 k}-c m_{1 k} y_{k}\right]-\left[\varphi w_{j} c r_{1 j}+c r_{2 j} w_{j}-\varphi w_{j} c r_{2 j}-c r_{1 j} w_{j}\right] \\
& -\left[\beta z_{n} c p_{1 n}+c p_{2 n} z_{n}-\beta z_{n} c p_{2 n}-c p_{1 n} z_{n}\right]
\end{aligned}
$$

s.t.

$$
\begin{array}{ll}
\sum_{n} \sum_{j} x_{n j}=d_{2}-\beta_{12} P_{2}+\beta_{22} P_{1} & \\
\sum_{j} \sum_{k} u_{j k}=r_{2}+\beta_{12} r p_{2}-\beta_{22} r p_{1} & \\
\sum_{k} u_{j k} \leq \sum_{n} x_{n j} & \forall j \\
\sum_{j} u_{j k}=\sum_{n} m_{k n} & \forall k \\
\sum_{k} m_{k n} \leq \sum_{j} x_{n j} & \forall n \\
\sum_{k} m_{k n} \leq \beta z_{n} c p_{1 n}-c p_{2 n} \beta z_{n}+z_{n} c p_{2 n} & \forall n \\
\sum_{j} u_{j k} \leq \alpha y_{k} c m_{1 k}-c m_{2 k} \alpha y_{k}+y_{k} c m_{2 k} & \forall k \\
\sum_{n} x_{n j} \leq \varphi w_{j} c r_{1 j}-c r_{2 j} \varphi w_{j}+w_{j} c r_{2 j} & \forall j \\
0 \leq \alpha y_{k} \leq \alpha \alpha_{k} & \forall
\end{array}
$$




$$
\begin{aligned}
& \alpha \alpha_{k}-M M_{k}\left(1-y_{k}\right) \leq \alpha y_{k} \leq M M_{k} y_{k} \\
& 0 \leq \varphi w_{j} \leq \varphi \phi_{j} \\
& \varphi \phi_{j}-M M_{j}\left(1-w_{j}\right) \leq \varphi w_{j} \leq M M_{j} w_{j} \\
& x_{n j}, u_{n j}, m_{n j} \geq 0 \\
& z_{n}, y_{k}, w_{j} \in\{0,1\}
\end{aligned}
$$

\section{Results OF SOLVING MODELS}

\subsection{Gathering and estimating data}

Reliable practical reports and historical data are used to collect and estimate economic and technical data. The input parameter values of the DEA model, i.e., the inputs and outputs considered in the model are taken from the organizations and sources, i.e., https://www.saftbatteries.com; https://www.sst-us.com/shop; https://www.azurspace.com; https://www.surrey.ac.uk and Sharif University of Technology, Amir-Kabir University, Khajeh-Nasir University, Iran University of Science and Technology, and experts in this field, which are presented in the Tables 1 and 2 for inputs and outputs of the DEA model.

TABLE 1. Value of the input criteria for DEA.

\begin{tabular}{llllll}
\hline \hline DMU & $\begin{array}{l}\text { Delivery } \\
\text { time }\end{array}$ & $\begin{array}{l}\text { Pieces supply } \\
\text { cost }\end{array}$ & DMU & $\begin{array}{l}\text { Delivery } \\
\text { time }\end{array}$ & $\begin{array}{l}\text { Pieces supply } \\
\text { cost }\end{array}$ \\
\hline DMU 1 & 6 & 4 & DMU 16 & 4 & 3 \\
DMU 2 & 1 & 9 & DMU 17 & 9 & 5 \\
DMU 3 & 2 & 4 & DMU 18 & 7 & 9 \\
DMU 4 & 5 & 3 & DMU 19 & 5 & 7 \\
DMU 5 & 9 & 1 & DMU 20 & 6 & 1 \\
DMU 6 & 4 & 3 & DMU 21 & 4 & 7 \\
DMU 7 & 7 & 8 & DMU 22 & 4 & 4 \\
DMU 8 & 2 & 5 & DMU 23 & 4 & 5 \\
DMU 9 & 7 & 6 & DMU 24 & 5 & 9 \\
DMU 10 & 7 & 1 & DMU 25 & 7 & 4 \\
DMU 11 & 1 & 8 & DMU 26 & 5 & 5 \\
DMU 12 & 6 & 7 & DMU 27 & 4 & 7 \\
DMU 13 & 5 & 1 & DMU 28 & 8 & 2 \\
DMU 14 & 6 & 9 & DMU 29 & 9 & 1 \\
DMU 15 & 4 & 5 & DMU 30 & 8 & 5 \\
\hline
\end{tabular}

\subsection{Applying data envelopment analysis}

In this section, we aim to evaluate 30 suppliers. In doing so, based on the criteria considered in Section 3 , the presented standard DEA will be used to evaluate suppliers. Suppliers that earn a minimum score based on the management perspective are taken into account to be the candidate locations for the optimization model. DEA models include standard and inverse models that are coded using GAMS software-version 24.1 and a Cplex solver is used to solve them. The flowchart of the algorithm used to obtain each decision unit's score is given in Figure 4. As can be seen, the DEA for decision unit $i$ is first solved and the $h_{b}$ value for that unit is extracted. Then, the reverse DEA model is also solved for the decision unit $i$ and the value of $h_{w}$ is acquired. Lastly, the value of $h_{l}$ is also achieved based on the values of $h_{b}$ and $h_{w}$. These steps are carried out for all DMUs and then are ranked as suppliers of CoPS.

Table 3 shows the efficiency and inefficiency scores for DMUs (i.e., suppliers) as well as their ranking. 
TABLE 2. Output metrics of data analysis criteria.

\begin{tabular}{llllllll}
\hline \hline DMU & $\begin{array}{l}\text { Financial } \\
\text { ability }\end{array}$ & $\begin{array}{l}\text { Network } \\
\text { development } \\
\text { ability }\end{array}$ & $\begin{array}{l}\text { Labor } \\
\text { force } \\
\text { capacity }\end{array}$ & DMU & $\begin{array}{l}\text { Delivery } \\
\text { time }\end{array}$ & $\begin{array}{l}\text { Pieces } \\
\text { supply } \\
\text { cost }\end{array}$ & $\begin{array}{l}\text { Labor } \\
\text { force } \\
\text { capacity }\end{array}$ \\
\hline DMU 1 & 5 & 6 & 2 & DMU 16 & 5 & 1 & 2 \\
DMU 2 & 8 & 9 & 9 & DMU 17 & 1 & 3 & 7 \\
DMU 3 & 3 & 8 & 4 & DMU 18 & 6 & 2 & 5 \\
DMU 4 & 3 & 2 & 8 & DMU 19 & 3 & 8 & 7 \\
DMU 5 & 3 & 9 & 6 & DMU 20 & 2 & 2 & 7 \\
DMU 6 & 4 & 7 & 9 & DMU 21 & 6 & 4 & 3 \\
DMU 7 & 1 & 5 & 4 & DMU 22 & 7 & 4 & 1 \\
DMU 8 & 4 & 5 & 9 & DMU 23 8 & 6 & 3 \\
DMU 9 & 7 & 4 & 8 & DMU 24 25 & 2 & 9 \\
DMU 10 & 9 & 5 & 8 & DMU 25 & 1 & 6 & 3 \\
DMU 11 & 4 & 2 & 3 & DMU 26 & 5 & 3 & 6 \\
DMU 12 & 9 & 4 & 5 & DMU 27 & 7 & 3 & 7 \\
DMU 13 & 6 & 7 & 1 & DMU 28 & 8 & 6 & 6 \\
DMU 14 & 5 & 1 & 3 & DMU 29 & 1 & 9 & 1 \\
DMU 15 & 8 & 2 & 1 & DMU 30 & 8 & 5 & 7 \\
\hline
\end{tabular}

TABLE 3. Results of DEA for rankings supplier.

\begin{tabular}{llllllllll}
\hline \hline DMU & $h_{b l}^{*}$ & $h_{w l}^{*}$ & $h_{l}^{*}$ & Rank & DMU & $h_{b l}^{*}$ & $h_{w l}^{*}$ & $h_{l}^{*}$ & Rank \\
\hline DMU 1 & 0.54 & 1.39 & 0.41 & 22 & DMU 16 & 0.71 & 1.1 & 0.40 & 23 \\
DMU 2 & 1 & 2.45 & 0.79 & 3 & DMU 17 & 0.41 & 1 & 0.20 & 28 \\
DMU 3 & 1 & 2.35 & 0.78 & 4 & DMU 18 & 0.39 & 1.29 & 0.31 & 25 \\
DMU 4 & 0.81 & 1.50 & 0.57 & 12 & DMU 19 & 0.59 & 2.12 & 0.56 & 13 \\
DMU 5 & 1 & 1.58 & 0.68 & 7 & DMU 20 & 0.98 & 1.14 & 0.55 & 14 \\
DMU 6 & 1 & 3.83 & 0.87 & 1 & DMU 21 & 0.59 & 1.33 & 0.42 & 21 \\
DMU 7 & 0.28 & 1 & 0.142 & 30 & DMU 22 & 0.90 & 1.12 & 0.50 & 18 \\
DMU 8 & 1 & 2.52 & 0.80 & 2 & DMU 23 & 0.94 & 1.94 & 0.71 & 6 \\
DMU 9 & 0.59 & 1.97 & 0.54 & 15 & DMU 24 & 0.531 & 1.144 & 0.328 & 24 \\
DMU 10 & 1 & 2.24 & 0.77 & 5 & DMU 25 & 0.46 & 1.09 & 0.27 & 27 \\
DMU 11 & 0.55 & 1.03 & 0.29 & 26 & DMU 26 & 0.56 & 2.04 & 0.54 & 16 \\
DMU 12 & 0.72 & 1.99 & 0.61 & 9 & DMU 27 & 0.69 & 2.09 & 0.61 & 10 \\
DMU 13 & 1 & 1.51 & 0.67 & 8 & DMU 28 & 0.75 & 1.79 & 0.6 & 11 \\
DMU 14 & 0.36 & 1 & 0.18 & 29 & DMU 29 & 1 & 1 & 0.5 & 19 \\
DMU 15 & 0.94 & 1 & 0.47 & 20 & DMU 30 & 0.60 & 1.79 & 0.52 & 17 \\
\hline
\end{tabular}

According to Table 3, when more informations are available about frontiers, the distinction between DMUs is increased. The minimum score for the index is considered to be 0.6 . More precisely, suppliers with a score above 0.6 are presumed to be as candidate locations. Accordingly, 10 suppliers are selected as candidate locations in the optimization model. This leads to the selection of more practical locations for suppliers, improving the model performance. On top of that, the decrease in the number of suppliers will contribute to a sharp reduction in the computational complexity of the optimization model that is one of the limitations of these kinds of models. 


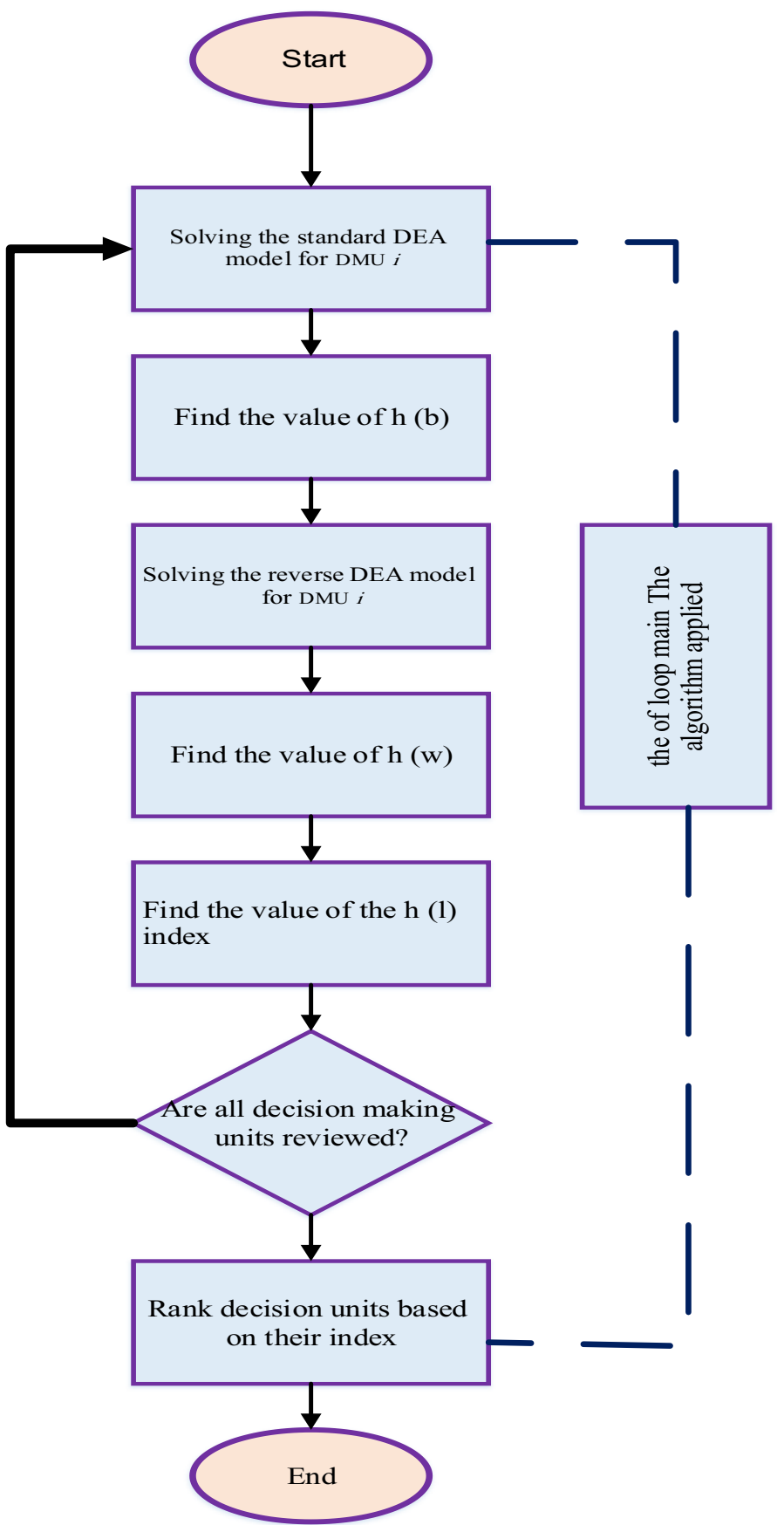

FiguRE 4. The algorithm implemented to obtain the ranking of DMUs. 
TABLE 4. Impact of capacity change on activated facilities.

\begin{tabular}{lllll}
\hline \hline \multirow{2}{*}{ Changes in the capacity } & \multicolumn{3}{c}{ Activated facilities } & \multirow{2}{*}{ Number of activated facilities } \\
\cline { 2 - 4 } & Supplier & Retailer & Recycling center & \\
\hline $0 \%$ & $1,2,3,4$ & $1,2,3$ & $1,3,4,5,6,7,8$ & 14 \\
$10 \%$ & $1,2,3,4$ & 1,2 & $1,3,5,6,7,8$ & 12 \\
$20 \%$ & $1,2,4$ & 1,2 & $1,3,5,6,7,8$ & 11 \\
$30 \%$ & $1,2,4$ & 1,2 & $1,3,5,6,7,8$ & 11 \\
$40 \%$ & $1,2,4$ & 1,2 & $1,3,5,6,7$ & 10 \\
$50 \%$ & $1,2,4$ & 1,2 & $3,5,6,7,8$ & 10 \\
$60 \%$ & $1,2,4$ & 1,2 & $1,3,5,6,7$ & 10 \\
$70 \%$ & $1,2,4$ & 1,2 & $1,3,5,6$ & 9 \\
$80 \%$ & 1,2 & 1,2 & $1,3,5,6$ & 8 \\
$90 \%$ & 1,2 & 1,2 & $3,4,6,7$ & 8 \\
$100 \%$ & 1,2 & 1,2 & $3,5,6,7$ & 8 \\
\hline
\end{tabular}

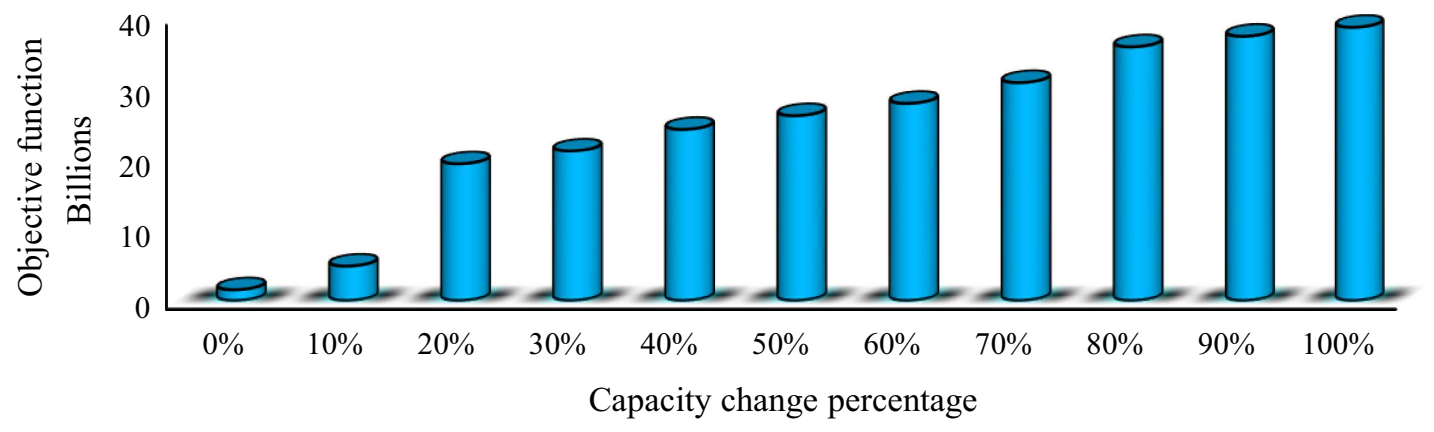

FigURE 5. Objective function variation due to changes in facilities' capacity.

\subsection{Implementing the mathematical model}

In this section, the optimization model will be solved and the relevant results will be extracted and discussed. The model has 2 supply chains, 8 retailers and 5 recycling centers. In addition, according to the presented DEA model, 10 suppliers are taken into account. The purpose of the proposed model is to simultaneously determine the strategic and tactical decisions, providing the optimal solution for the model. Likewise, the robust optimization model is capable of rendering a stable structure under different uncertainties for the model. The robust model was implemented in GAMS software and Cplex solver was employed to solve it. The proposed model contains 49 equations, 190 continuous variables, and 17 binary variables. In addition, the CPU time for solving the model is $2.15 \mathrm{~s}$.

Table 4 shows the number of facilities pertaining to capacity changes. As can be seen, as the facility capacity increases, the supply chain becomes a decentralized chain of supply. Speaking intuitively, with an increase in the facilities' capacity, fewer facilities are needed to meet demand in the supply chain.

In Figure 5, the effect of storage capacity on the objective function changes is examined. It is evident that as capacity enlarges, the chain's profits also increase. It is also observed that as capacity gets to be larger, the rate of increase in profit decreases. For example, increasing capacity from $10 \%$ to $20 \%$ contributes to increased profits of about $30 \%$, while as the capacity increases from $80 \%$ to $90 \%$ the rise is only $4 \%$. In this manner, it can be concluded that an increase in capacity will result in more profits at low capacity.

Figure 6 shows retail price changes with respect to changes in product sale's revenue from the manufacturer to retailer, and sale's revenue of recycled products from retailer to recycling center. As shown in Figure 6, the 


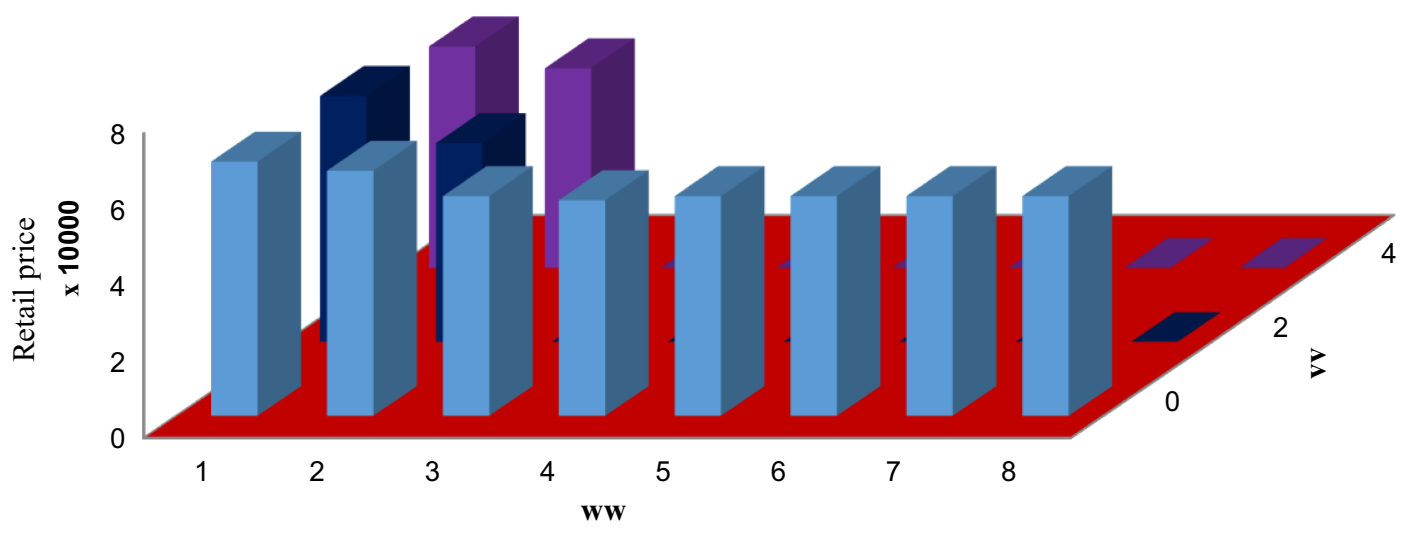

FIGURE 6. Changes in price due to the objective function's average.

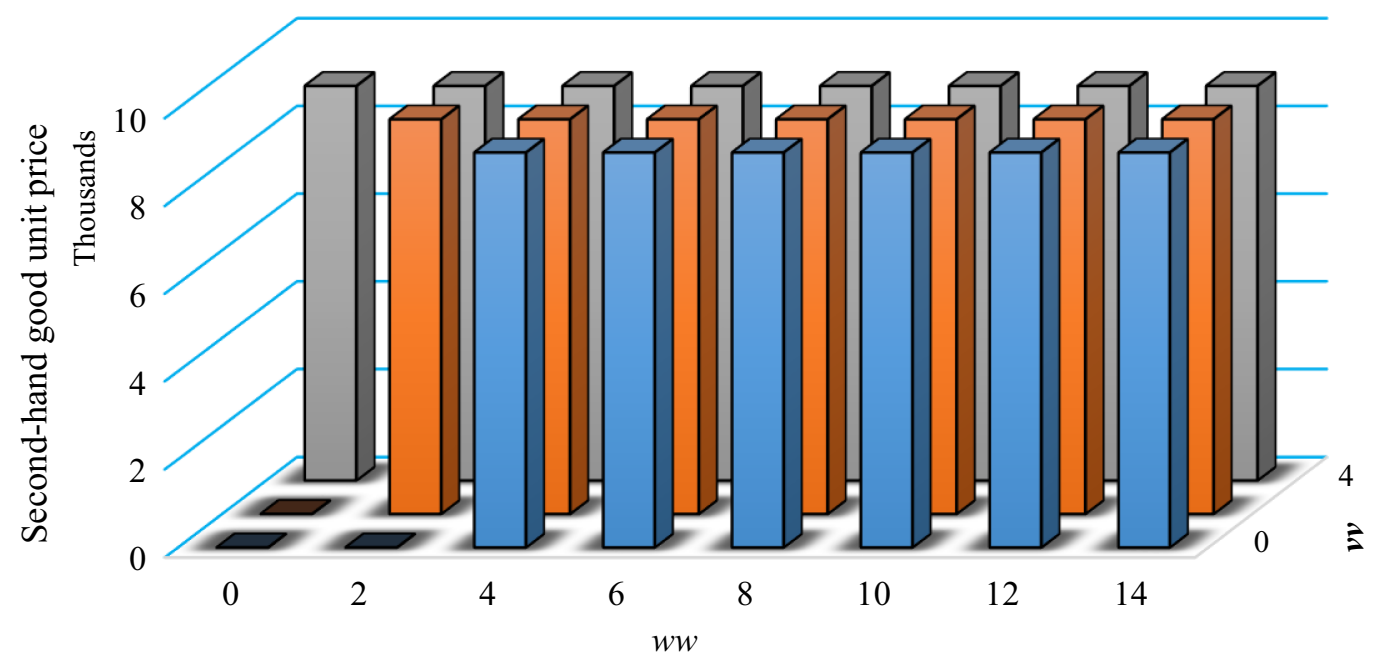

FIGURE 7. Changes in prices of second-hand goods due to the objective function's average.

retail price is lessened with an increase in the sale's factor of the product from manufacturer to retailer. The reason for this decrease in price is that when the sale's revenue from the manufacturer to the retailer rises, the model prefers to increase the volume of goods flow between the production center and the retailer. The retail price should therefore be reduced to increase demand and thereby increase the volume of goods flow between the production center and the retailer. Also, it is observed that as the sale's revenue of recycled products from the retailer to the recycling center ascents, the retail price descends. The rationale behind this is that by increasing the sale's revenue of recycled products from the retailer to the recycling center, the model prefers to escalate the volume of second-hand goods between the retailer and the recycling center. This necessitates an upward volume of goods' flow between the production center and the retailer, in which the retail price will diminish.

Figure 7 shows the changes in the price of second-hand goods relative to changes in product sale's revenue from manufacturers to retailers, and recycled products' sale revenue from retailers to the recycling center. According to this figure, the price of second-hand goods increases as the product's sales coefficient increases from manufacturers to retailers. The reason is that by increasing the coefficient of sale's revenue from the manufacturer to the retailer, the model prefers to increase the volume of goods' flow between the production 


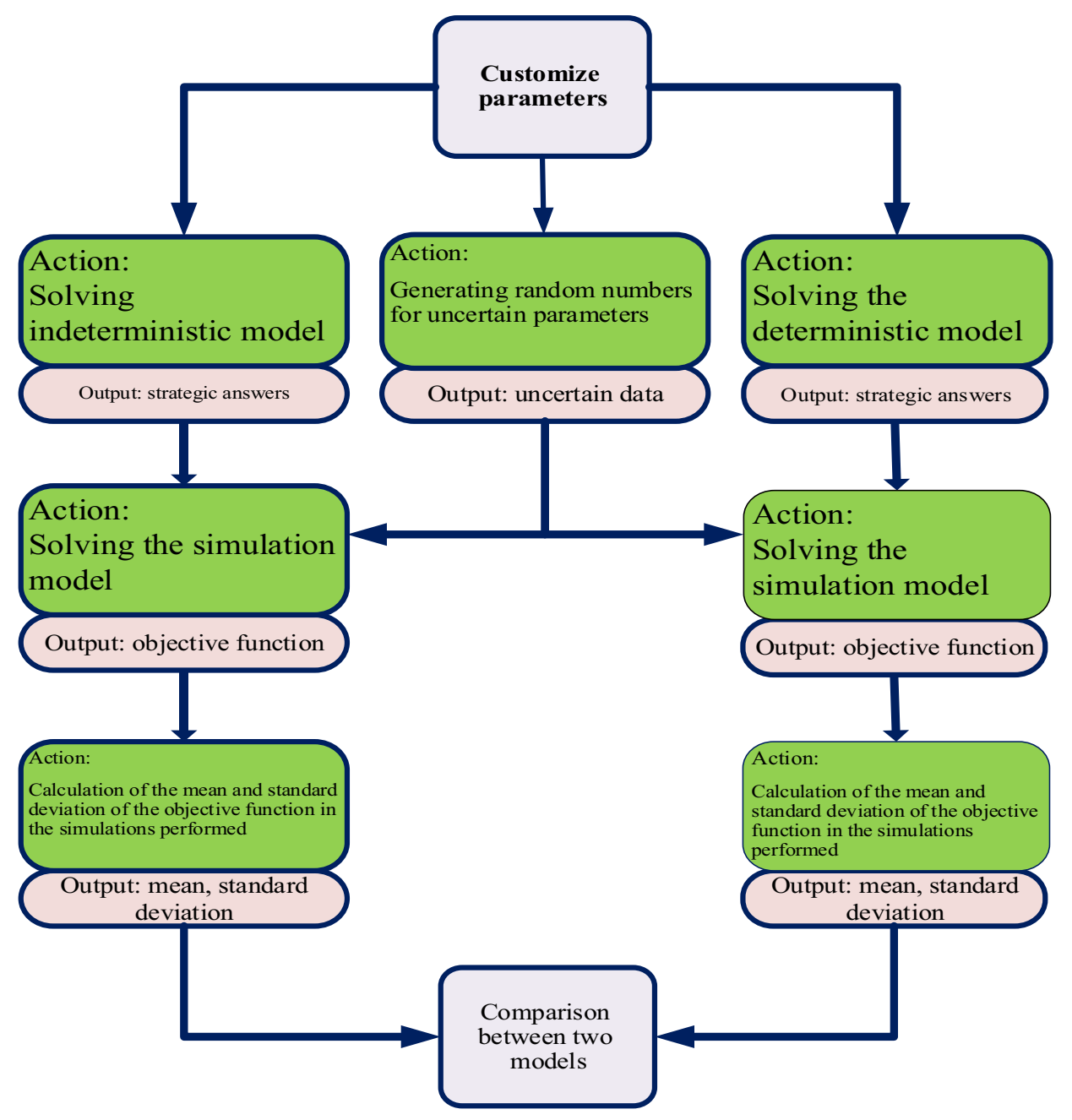

FiguRE 8. Comparison of robust and deterministic model based on the objective function's average.

center and the retailer. Increasing this amount enhances the volume of second-hand goods between the retailers and the recycling center, which in turn expand the unit price of second-hand goods. It is also observed that with the increase in the sales' revenue of recycled products from the retailer to the recycling center, the price of second-hand goods goes up. The reason is that by escalating the sale's revenue of recycled products from the retailer to the recycling center, the model tends to increase the volume of second-hand goods between the retailer and the recycling center. That's why the unit price of second-hand goods' will rise.

To evaluate the effectiveness and desirability of the proposed model, the performance of the model is solved using a deterministic model. In the deterministic model, the value of the deterministic parameters is set to the mean value. The proposed method for comparing the two models is shown below. As illustrated in Figure 8, both models (i.e., deterministic and robust) are solved first, and then the variables' values are obtained. Also, 100 simulations are performed for uncertain parameters. Then, the obtained variables are placed in the simulation model, which has the following compact form:

$$
\operatorname{Max} o b j=f_{\text {real }} y^{*}+c_{\text {real }} x^{*}-v R
$$




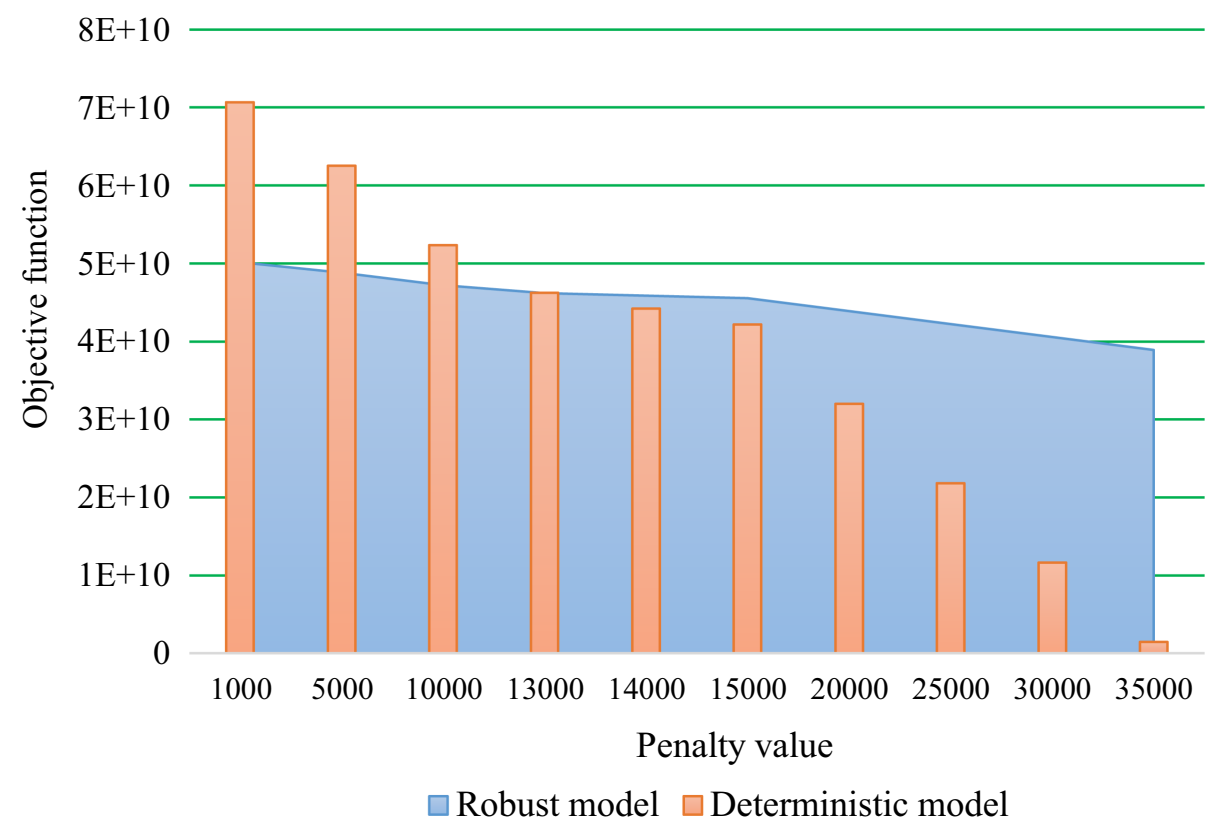

FiguRE 9. Comparison of robust and deterministic model based on the objective function's average.

$$
\begin{aligned}
& A x^{*}+R \leq \operatorname{cap}_{\text {real }} y^{*} \\
& B x^{*}=d \\
& E x^{*} \leq 0 \\
& G x^{*}=0 \\
& R \geq 0 .
\end{aligned}
$$

So, $y^{*}$ and $x^{*}$ represent the optimal value of the problem variables, respectively. The $f_{\text {real }}$ and $c_{\text {real }}$ vectors are random number vectors generated for the objective function coefficients. The matrices $A, B, E$, and $G$ are the constraint coefficients matrix. Also, $c a p_{\text {real }}$ and $d$ are the numbers generated for the capacity and the righthand side numbers, respectively. It should be noted that $R$ is a positive variable, if the constraint limitations is violated. Meanwhile $v$ is also a penalty when the capacity limitation is violated.

Note that 100 simulation models are solved for each of the robust and deterministic models. Lastly, the mean and variance of the simulation models are calculated to compare both models.

As presented in Figure 7, the deterministic model performs better as long as the impossibility penalty is less than 13000 . When the penalty parameter is equal to 13000 , the two models will have the same performance. For values that are more than 13000 , the performance of the robust model will be improved. The higher the penalties eventuates in the better the performance of the robust model and also the received profit. For example, when the penalty parameter is equal to 20000 , the performance of the robust model is about $27 \%((4.39 E+$ $10-3.2 E+10) / 4.93 E+10)$ better than the deterministic one. In the same manner, when the penalty parameter is equal to 30000 , the performance of the robust model is about $71 \%((4.06 E+10-1.16 E+10) / 4.06 E+10)$ better than the deterministic model.

Figures 9 and 10 compares the performance of the two models in terms of variance. As can be seen in this figure, the robust model performs much better than the deterministic one for different fine values. It should be noted that by increasing the number of the penalty parameter, the robust model performs better than the determinant one. The advantage of the robust model in terms of standard deviation over the deterministic 
Objective function's variance

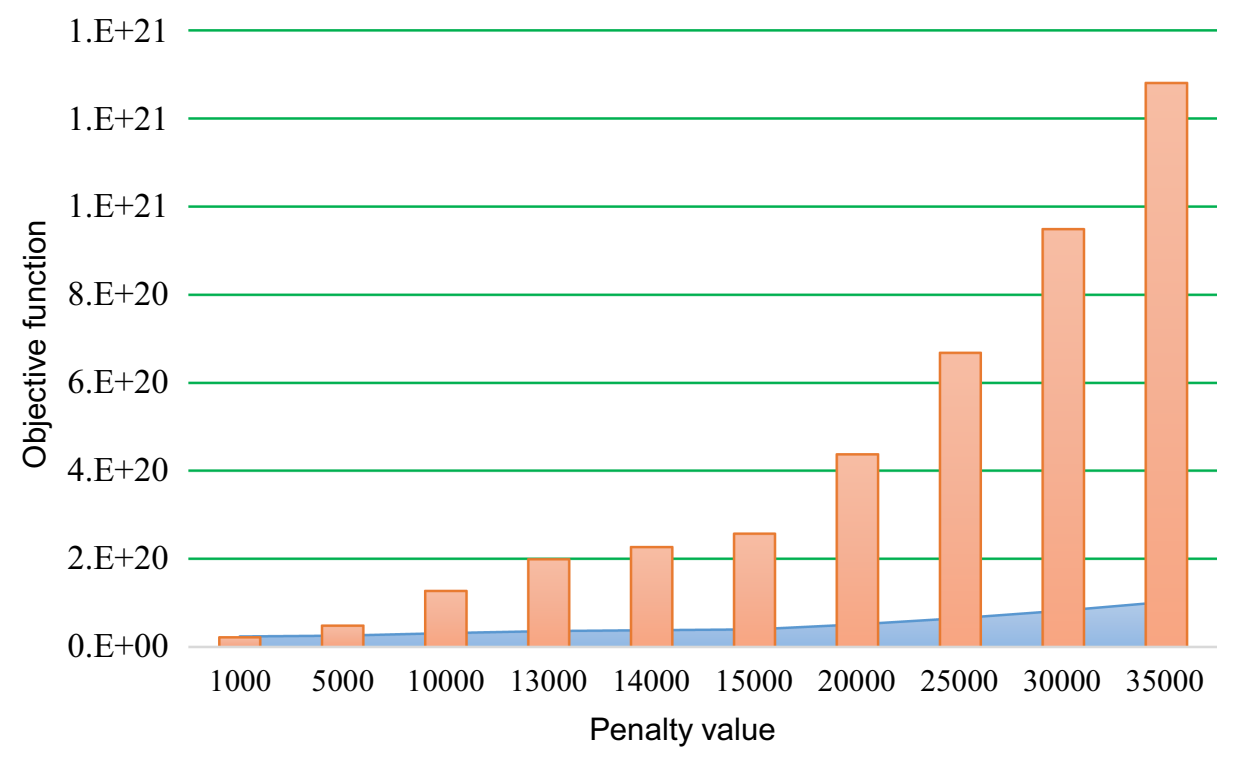

$\square$ Robust model $\square$ Deterministic model

Figure 10. Comparison of robust and deterministic model based on the objective function's variance.

model indicates that the solutions of this model are not sensitive to uncertain parameters. More precisely, the robust model can provide a stable configuration for the desired supply chain.

\section{Conclusions}

Different areas of CoPS are the most value-added in the economic development and competitiveness of various countries. Likewise, one of the key requirements for entering this field is selecting the right supplier for CoPS pricing. The right supplier in addition to reducing costs increases competition and speeds up progress to achieve this aim. In this sense, a hybrid DEA-mathematical model for economic pricing of CoPS in a competitive closed-loop supply chain network under uncertainty is presented. Using the DEA method, the first stage assesses different CoPS suppliers based on a set of economic, technical, and geographical criteria. The advantage of this evaluation is choosing appropriate suppliers, and reducing complexity of the original model. In the second phase, the strategic and tactical decisions simultaneously are determined using a robust optimization model, providing a fully optimal solution to the model. The presented model is capable of providing a stable structure under different uncertainties.

A case study is used to evaluate the effectiveness and applicability of the proposed method, in which important managerial results are extracted. The results corroborates that using the presented DEA method will increase the distinction between the decision options. The mathematical model also endorses that increasing the capacity of the facility contributes to a decentralized supply chain. In other words, as capacity increases, fewer facilities will be needed to meet demand in the supply chain. In addition, in accordance with the model, it is found that the relationship between capacity increase and profit is linear and upward. Moreover, with the increase in the product sales coefficient of the manufacturer to the retailer and consequently his revenue, the retail price decreases. It should also be noted that with the growth of sales revenue of recycled products from retailers to 
the recycling center, the unit price of second-hand goods enhances. On top of that, the results envice that the robust model on average has a more stable performance than the deterministic one.

This study is one of the first studies in the field of complex product optimization. Accordingly, promising future research avenues can be recommended as follows:

- Considering disruption to suppliers with the aid of a scenario-based mathematical model.

- Taking into account other decision-making techniques like AHP, TOPSIS, etc. for evaluating the suppliers.

- Providing an exact algorithm to solve the proposed model.

Acknowledgements. For example, the Benders decomposition or Lagrangian relaxation algorithm method can be used.

\section{REFERENCES}

[1] R. Aboolian, O. Berman and D. Krass, Competitive facility location and design problem. Eur. J. Oper. Res. 182 (2007) 40-62.

[2] V. Acha, A. Davies, M. Hobday and A. Salter, Exploring the capital goods economy: complex product systems in the UK. Ind. Corporate Change 13 (2004) 505-529.

[3] E.J. Anderson and Y. Bao, Price competition with integrated and decentralized supply chains. Eur. J. Oper. Res. 200 (2010) $227-234$.

[4] A. Atasu, V.D.R. Guide Jr and L.N. Van Wassenhove, So what if remanufacturing cannibalizes my new product sales? California Manage. Rev. 52 (2010) 56-76.

[5] R.D. Banker, Estimating most productive scale size using data envelopment analysis. Eur. J. Oper. Res. 17 (1984) $35-44$.

[6] M. Bashiri, H. Badri and J. Talebi, A new approach to tactical and strategic planning in production-distribution networks. Appl. Math. Model. 36 1703-1717.

[7] O. Berman and D. Krass, Flow intercepting spatial interaction model: a new approach to optimal location of competitive facilities. Location Sci. 6 (1998) 41-65.

[8] T. Boyaci and G. Gallego, Supply chain coordination in a market with customer service competition. Prod. Oper. Manage. 13 (2004) 3-22.

[9] P. Chanintrakul, A.E. Coronado Mondragon, C. Lalwani, C.Y. Wong, Reverse logistics network design: a state-of-the-art literature review. Int. J. Bus. Perform. Supply Chain Model. 1 (2009) 61-81.

[10] A. Charnes, W.W. Cooper and E. Rhodes, Measuring the efficiency of decision making units. Eur. J. Oper. Res. 2 (1978) 429-444.

[11] J.-M. Chen and C.-I. Chang, The co-opetitive strategy of a closed-loop supply chain with remanufacturing. Transp. Res. Part E: Logistics Transp. Rev. 48 (2012) 387-400.

[12] T.-M. Choi, Y. Li and L. Xu, Channel leadership, performance and coordination in closed loop supply chains. Int. J. Prod. Econ. 146 (2013) 371-380.

[13] S.K. Das, S.K. Roy and G.W. Weber, Application of type-2 fuzzy logic to a multi-objective green solid transportation-location problem with dwell time under carbon tax, cap and offset policy: fuzzy vs. Non-fuzzy techniques. IEEE Trans. Fuzzy Syst. 28 (2020) $2711-2725$.

[14] A. Davies and T. Brady, Policies for a complex product system. Futures 30 (1998) 293-304.

[15] A. Davies and M. Hobday, The Business of Projects: Managing Innovation in Complex Products and Systems. Cambridge University Press (2005).

[16] P. De Giovanni and G. Zaccour, A two-period game of a closed-loop supply chain. Eur. J. Oper. Res. 232 (2014) $22-40$.

[17] O. Dedehayir, T. Nokelainen and S.J. Mäkinen, Disruptive innovations in complex product systems industries: a case study. J. Eng. Technol. Manage. 33 (2014) 174-192.

[18] R. Dekker, M. Fleischmann, K. Inderfurth, L.N. van Wassenhove, Reverse Logistics: Quantitative Models for Closed-Loop Supply Chains. Springer Science \& Business Media (2013).

[19] B. Du and S. Guo, Production planning conflict resolution of complex product system in group manufacturing: a novel hybrid approach using ant colony optimization and Shapley value. Comput. Ind. Eng. 94 (2016) 158-169.

[20] B. Du, S. Guo, X. Huang, Y. Li and J. Guo, A Pareto supplier selection algorithm for minimum the life cycle cost of complex product system. Expert Syst. App. 42 (2015) 4253-4264.

[21] D. Dubois and H. Prade, Possibility theory. In: Computational Complexity. Springer, New York (2012) $2240-2252$.

[22] R.Z. Farahani, S. Rezapour, T. Drezner and S. Fallah, Competitive supply chain network design: an overview of classifications, models, solution techniques and applications. Omega 45 (2014) 92-118.

[23] M.J. Farrell, The measurement of productive efficiency. J. R. Stat. Soc. Ser. A (General) 120 (1957) $253-281$.

[24] M. Ferguson and B. Toktay, The effect of external competition on recovery strategies. Georgia Institute of Technology College of Business Working Paper (2004).

[25] S. Green, Principles of Biopsychology Lawrence Erlbaum Associates Ltd. Hove, England (1994).

[26] T.G. Gutowski, S. Sahni, A. Boustani and S.C. Graves, Reply to Comment on "Remanufacturing and Energy Savings". Environ. Sci. Technol. 45 (2011) 7604-7604. 
[27] D. Hammond and P. Beullens, Closed-loop supply chain network equilibrium under legislation. Eur. J. Oper. Res. 183 (2007) 895-908.

[28] K.L. Hansen and H. Rush, Hotspots in complex product systems: emerging issues in innovation management. Technovation 18 (1998) 555-590.

[29] S. Heilpern, The expected value of a fuzzy number. Fuzzy Sets Syst. 47 (1992) 81-86.

[30] C.-J. Ho, Evaluating the impact of operating environments on MRP system nervousness. Int. J. Prod. Res. 27 (1989) $1115-1135$.

[31] M. Hobday, Editor's Introduction: The Scope of Martin Bell's Contribution. (2007).

[32] M. Hobday, The project-based organisation: an ideal form for managing complex products and systems? Res. Policy 29 (2000) 871-893.

[33] I.-H. Hong and J.-S. Yeh, Modeling closed-loop supply chains in the electronics industry: a retailer collection application. Transp. Res. Part E: Logistics Transp. Rev. 48 (2012) 817-829.

[34] C. Hongzhuan, F. Zhigeng, L. Sifeng and M. Shuai, The optimal cost-sharing incentive model of main manufacturer-suppliers for complex equipment under grey information. Paper presented at the Proceedings of 2013 IEEE International Conference on Grey systems and Intelligent Services (GSIS) (2013).

[35] M. Inuiguchi and J. Ramık, Possibilistic linear programming: a brief review of fuzzy mathematical programming and a comparison with stochastic programming in portfolio selection problem. Fuzzy Sets Syst. 111 (2000) 3-28.

[36] I. Karakayali, H. Emir-Farinas and E. Akcali, An analysis of decentralized collection and processing of end-of-life products. J. Oper. Manage. 25 (2007) 1161-1183.

[37] S. Khalilpourazari, A. Mirzazadeh, G.-W. Weber and S.H.R. Pasandideh, A robust fuzzy approach for constrained multiproduct economic production quantity with imperfect items and rework process. Optimization 69 (2019) 63-90.

[38] W. Klibi, A. Martel and A. Guitouni, The design of robust value-creating supply chain networks: a critical review. Eur. J. Oper. Res. 203 (2010) 283-293.

[39] H. Kurata, D.-Q. Yao and J.J. Liu, Pricing policies under direct vs. indirect channel competition and national vs. store brand competition. Eur. J. Oper. Res. 180 (2007) 262-281.

[40] B. Liu and K. Iwamura. A note on chance constrained programming with fuzzy coefficients. Fuzzy sets and Syst. 100 (1998) 229-233

[41] S.C.H. Leung, S.O.S. Tsang, W.-L. Ng and Y. Wu, A robust optimization model for multi-site production planning problem in an uncertain environment. Eur. J. Oper. Res. 181 (2007) 224-238.

[42] O. Listeş, A generic stochastic model for supply-and-return network design. Comput. Oper. Res. 34 (2007) $417-442$.

[43] Y. Liu, S. Fang, Z. Fang and K.W. Hipel, Petri net model for supply-chain quality conflict resolution of a complex product. Kybernetes 41 (2012) 920-928.

[44] R. Lotfi, Y.Z. Mehrjerdi, M.S. Pishvaee, A. Sadeghieh and G.-W. Weber, A robust optimization model for sustainable and resilient closed-loop supply chain network design considering conditional value at risk. Numer. Algebra Control Optim. 11 (2021) 221-253.

[45] T.W. McGuire and R. Staelin, An industry equilibrium analysis of downstream vertical integration. Marketing Sci. 2 (1983) $161-191$.

[46] E. Özceylan, T. Paksoy and T. Bektaş, Modeling and optimizing the integrated problem of closed-loop supply chain network design and disassembly line balancing. Transp. Res. Part E: Logistics Transp. Rev. 61 (2014) 142-164.

[47] E. Ozceylan, B. Ozkan, M. Kabak and M. Dagdeviren, A survey on spherical fuzzy sets and clustering the literature. Paper presented at the International Conference on Intelligent and Fuzzy Systems (2020).

[48] E.D. Özdemir, M. Härdtlein, T. Jenssen, D. Zech and L. Eltrop, A confusion of tongues or the art of aggregating indicators - Reflections on four projective methodologies on sustainability measurement. Renew. Sustainable Energy Rev. 15 (2011) $2385-2396$.

[49] T. Paksoy, A. Çalik, A. Kumpf and G.W. Weber, A new model for lean and green closed-loop supply chain optimization. In: Lean and Green Supply Chain Management. Springer (2019) 39-73.

[50] P. Peykani and J. Gheidar-Kheljani, Performance appraisal of research and development projects value-chain for complex products and systems: the fuzzy three-stage DEA approach. J. New Res. Math. 6 (2020) 41-58.

[51] M.S. Pishvaee, J. Razmi and S.A. Torabi, Robust possibilistic programming for socially responsible supply chain network design: a new approach. Fuzzy Sets Syst. 206 (2012) 1-20.

[52] M.S. Pishvaee, J. Razmi and S.A. Torabi, An accelerated Benders decomposition algorithm for sustainable supply chain network design under uncertainty: a case study of medical needle and syringe supply chain. Transp. Res. Part E: Logistics Transp. Rev. 67 (2014) 14-38.

[53] Q. Qiang, K. Ke, T. Anderson and J. Dong, The closed-loop supply chain network with competition, distribution channel investment, and uncertainties. Omega 41 (2013) 186-194.

[54] C. ReVelle, A.T. Murray and D. Serra, Location models for ceding market share and shrinking services. Omega 35 (2007) $533-540$.

[55] S. Rezapour and R.Z. Farahani, Strategic design of competing centralized supply chain networks for markets with deterministic demands. Adv. Eng. Softw. 41 (2010) 810-822.

[56] P.J. Rushton, M.T. Bokowiec, S. Han, H. Zhang, J.F. Brannock, X. Chen, T.W. Laudeman and M.P. Timko, Tobacco transcription factors: novel insights into transcriptional regulation in the Solanaceae. Plant Physiol. 147 (2008) $280-295$. 
[57] M. Safdari Ranjbar, T.-Y. Park and M. Kiamehr, What happened to complex product systems literature over the last two decades: progresses so far and path ahead. Technol. Anal. Strategic Manage. 30 (2018) 948-966.

[58] W.-F. Shen, D.-Q. Zhang, W.-B. Liu and G.-L. Yang, Increasing discrimination of DEA evaluation by utilizing distances to anti-efficient frontiers. Comput. Oper. Res. 75 (2016) 163-173.

[59] O. Solgi, J. Gheidar-Kheljani, E. Dehghani and A. Taromi, Resilient supplier selection in complex product and its subsystems' supply chain under uncertainty and risk disruption: a case study for satellite components. Sci. Iran. (2019). DOI: 10.24200/sci.2019.52556.2773.

[60] O. Solgi, J. Gheidar-Kheljani, M. Saidi-Mehrabad and E. Dehghani, Implementing an efficient data envelopment analysis method for assessing suppliers of complex product systems. J. Ind. Syst. Eng. 12 (2019) 113-137.

[61] T. Sueyoshi and M. Goto, Measurement of Returns to Scale and Damages to Scale for DEA-based operational and environmental assessment: How to manage desirable (good) and undesirable (bad) outputs? Eur. J. Oper. Res. 211 (2011) 76-89.

[62] E.B. Tirkolaee, A. Goli and G.W. Weber, Fuzzy mathematical programming and self-adaptive artificial fish swarm algorithm for just-in-time energy-aware flow shop scheduling problem with outsourcing option. IEEE Trans. Fuzzy Syst. 28 (2020) $2772-2783$.

[63] A.A. Tsay and N. Agrawal, Channel dynamics under price and service competition. Manuf. Serv. Oper. Manage. 2 (2000) 372-391.

[64] H. Üster, G. Easwaran, E. Akçali and S. Çetinkaya, Benders decomposition with alternative multiple cuts for a multi-product closed-loop supply chain network design model. Nav. Res. Logistics (NRL) $\mathbf{5 4}$ (2007) 890-907.

[65] J. Wei, K. Govindan, Y. Li and J. Zhao, Pricing and collecting decisions in a closed-loop supply chain with symmetric and asymmetric information. Comput. Oper. Res. 54 (2015) 257-265.

[66] O. Wu and H. Chen, Chain-to-Chain Competition Under Demand Uncertainty. The University of British Columbia, Vancouver (2003) $1-10$.

[67] T. Xiao and D. Yang, Price and service competition of supply chains with risk-averse retailers under demand uncertainty. Int. J. Prod. Econ. 114 (2008) 187-200.

[68] D. Zhang, A network economic model for supply chain versus supply chain competition. Omega 34 (2006) $283-295$.

[69] J. Zhao, W. Tang and J. Wei, Pricing decision for substitutable products with retail competition in a fuzzy environment. Int. J. Prod. Econ. 135 (2012) 144-153. 